\title{
The Particularity of Film Translation
}

\author{
Xianhua Meng \\ Linyi University Feixian College \\ Feixian ,Linyi, Shandong, China \\ mengxh18@163.com
}

\author{
Yan Chen \\ Linyi University Feixian College \\ Feixian ,Linyi, Shandong, China \\ 97chenyan@sohu.com
}

\begin{abstract}
The film translation, as a branch of literary translation, complies with the general principles of literary translation. However, the particularity of the film and television art determines the translation has difference with other literary works. In this paper, the author focus on five aspects to discuss the particularity of film and television works translation, as well as the problems that should be paid attention to in translation.
\end{abstract}

Keywords-film and television translation; translation principles; language characteristics; particularity

\section{INTRODUCTION}

Along with the constant development of reform and opening up, the communication of China and the other countries all over the world comes into a new comprehensive, rapid development stage in politics, economy, culture and other various aspects. The channels and forms in culture communication are becoming more and more diversified. As a cosmopolitan, popular art form, undoubtedly, film and TV occupies an important position in the communication. We had many excellent Chinese films abroad; at the same time, we also introduced a large number of outstanding foreign films every year, which brought exotic cultural feast for the audience. This massive film and television cultural exchange of film translation put forward the major tasks and challenges. Film translation is a very important step in the process of film and television transmission. The quality of the translation directly affects the film art and attraction, and also influences our preference for the film. But for various reasons, the current level of film translation are intermingled, which caused the quality of many good movie translation works have been artificially reduced. Therefore, how to understand and appreciate and accurate the translation is particularly important. At the same time, the particularity of the film translation is not allowed to ignore.

\section{THE PARTICULARITY OF AUDIO-VISUAL TRANSLATION}

As a branch of literary translation, film translation has in common with literature translation, complying with the general principles of literary translation. But in a large extent, it's still subject to the special features of the film and television art .Film works, first of all, is a "tangible audio echoism combination of art". The picture and sound (voice, music, etc.) complete with each other in the film. Pictures and sounds in the film is just a flash. Especially, the voice doesn't give the audience any chance to think about. Therefore, the language of the film and television play should be very popular and easy to understand. Besides, in order to improve their attendance and ratings, all the films and television plays try their best to encourage the audience to enjoy the programs. All these put forward special requirements for the language of film translation.

\section{A. Orality}

The language of the film is primarily spoken out by actors, the audience must use ears to listen to. In other words, while watching a film and television play, the audience must be in the eyes and ears at the same time, scanning the pictures and listening to the dialogue both at the same time. It is advantageous for the audience to understand the film and TV character's dialogue when videos and images appeared at the same time vividly. But the dialogues appear only in the form of verbal language. It's difficult to achieve the effect as the written form in many cases. The actors in the process of the voice, for example, the Chinese homophones abnormity meaning words tend to cause some trouble. In English, "he, she, and it" translated into"他, 她, 它"respectively, but their pronunciation is exactly the same in Chinese, namely " ta "pronunciation. However, it is difficult to distinguish among "he" or" she" or "it", for the same pronunciation in Chinese. In English, "They all come", translated into "他们全部来了" is quite proper in written language. But in the dubbed film, this translation will appear ambiguity. Does it mean" They all come"他们全部来了, or "They all don't come"? 他们全不来 了"Another example. "He beat her" translated into Chinese as "他打了她" . In this way, the reader will not misunderstand. But the audience was nerve-racking. "Did he beat her?"Or "Did she beat him"? In this case, film translators should be flexible to use some other ways to avoid this ambiguity.

\section{B. Popularity}

Reading literary works demands a certain level of education, but even a illiteracy can watch a film and television dialogues. While watching TV, the whole family members are sitting together. That requires the film and television dialogues must suit both refined and popular tastes. It is destined that film is a kind of popular art from the date of birth, which is the commercial in nature itself that matters much. In order to get the highest benefit with the lowest cost, the directors managed to promote their film works. Only in this way can they achieve their commercial purposes. Since the potential audience of the film and television play is the public, its content should conform to the general audience's culture and education level, and it also should be within the scope of the general audience 
can accept. Losing the audience market means lost film inherent potential value. Viewers first catch the dialogue, and then understand and enjoy the film and television play. The content of overall value can be reflected at last. As it is known to all, the language of film and television play should be translated easier to understand except in some special occasions, such as speech, reading, etc. In the movie Forrest Gump, Forrest has repeatedly referred " stupid is as stupid does" translated into "䖭人就做蚌事 "in Chinese. This translation is quite good, for it's not only popular but also fluent, and certainly makes great achievement.

\section{Instantanity}

The instantaneity of the film translation language is determined by the characteristics of film and television play itself. According to the plot development, film images and sounds are fleeting. The language of the general of literary works, such as prose, fiction, it appears in the form of a written language on the paper, so that readers can read again and again, and even weigh every word. It's quite different from the film appreciating. While watching a film or television, the audience didn't have any chance to reread the dialogues. It's impossible for the audience to read back during watching. We'd better give up when we missing the dialogue in the play, instead of wondering. Otherwise, we'll miss the next part. It's similar to the listening text. When we missed the question, we'd better give up at once and prepared for the next one. As a result, the instantaneity of the film requires the language of translation must be easy to understand for the audience.

\section{Synthesizability}

The integration refers to the act of combing into an integral whole. It means that the language, music and dynamic images are influenced and complement with each other. All those parts are closely linked together. The actor's body language, such as nodding, shaking the head, and hand gestures are parts of the film language. In this way, we can conclude that the film language including two parts: verbal language and nonverbal languages .This is different from general literature. And verbal and nonverbal languages are not independent and mutually exclusive. In particular, the verbal language is the foundation of the nonverbal language; while nonverbal language plays a limit and supplementary role of verbal language.

Tessa: So we shouldn't out murder rule. (Murder Call)

Lance: No. (Shaking his head)

\section{--Murder Alarm}

This is the dialogue between the two detectives. Tessa said it can't rule out homicide, Lance answered "No". In disjunctive questions, the standard of using "Yes" or "No" is determined by the fact itself. When the standard is the truth itself, we will choose "Yes"; otherwise, choose" No". So according to English habits, "No" here refers to the fact itself is negative, namely "does not exclude the homicide". In other words, he is in favor of Tessa's point of view. In Chinese, however, as long as the responder agrees with the questions in the point of view, we can use "yes", the opposite with "no". Therefore, according to Chinese expressions, the dialogue should be translated into:

Tessa: 因此不能排除他杀。
Lance: 是的.

But on the screen , Lance shook his head in response. It is self-contradicted that shaking one's head to show favor at the same time, isn't it? (Shaking one's head had negative meaning both in Chinese and English culture.) At that rate, the audience will be in puzzle: what's Lance's attitude towards the murder? Is he in favor of a homicide or against? As a result, "No" here should be translated as "can't" (不能) which means" I can't rule out a homicide". So in film translation , we must always pay attention to the consistency and integration between sound and image. Use proper words flexibly to reflect the particularity in the process of film and television language translation.

\section{E. Conciseness}

Conciseness here refers to the certain restrictive of the translation words in the film translation. Use as equal or similar unit as possible to express the primitives (generally speaking a syllable in English equivalent of a Chinese character in Chinese). The language of the translation should meet the simple and clear standards, because the language of the content itself is relatively simple. Works such as novels, prose, and poetry translation in this limit is much easier than in film translation. If the film interpreter not pay attention to the word limits, that would leave the voice actor in trouble. In that case, the sound and image will hardly cooperated, and next lead to distortion, or even affect or destroy the character shaping and emotional expressions, which affect the effect of the whole content of appreciation.

\section{He came from P.R.C.}

\section{Translation: 他是从中华人民共和国来的。}

Here the original sentences using the "P.R.C." instead of "People's Republic of China" .It follows the rule of simplicity of film translation. There are only six syllables in the original sentence, but twelve in the translation. It's no doubt that the translation have been lagged behind. So, we'd better translated into “他来自中国”, or directly translated into“他是中国人”. Only five words, however, are more likely to achieve the purpose of dubbing and lip sync without changing the meaning.

\section{CONCLUSION}

Film translation is different from the ordinary translation. In view of the particularity, we'd better base on the domestic audience during the process of translation, and choose their native language with the most similar, closest and familiar words as well as culture to translate. All the words should be easy to accept. It's a great challenge for the film interpreters to select accurate and vivid words to reproduce the ideological content and artistic characteristics of the film.

To guarantee the accuracy of the translation language vividly and at the same time, we should also pay attention to the characteristics of language and the characteristics of the characters. Although there is a lot of particularity of film translation, including many obstacles as well, as long as we continue to practice, and accumulate experience from practice, draw our lessons, we are certain to make a great achievement 
in film translation. According to the film translation, we can catch the point of the original characters, reproduce the ideological content leave more and more audience fall in love with our dubbed films. In short, film translation is not only a difficulty but also a focal point. It is also a topic worthy of further study of film interpreter. We are on the tiptoe of expectation for the spring of recovery of the film translation career.

\section{REFERENCE}

[1] Qian Shaochang. Film translation-more and more important in translation field territory[J].Chinese Translators Journal, 2000 (01) : 61-65.

[2] Zhao Chunmei. Trsnslstion into Chinese of Film ScriPts and ScriPst of TV Drama Series Four Main Conflieting Demands [J].Chinese Translators Journal, 2002 (04).

[3] Peter Newmark. The Approaches to Translation [M]. Shanghai;Shanghai Foreign language Education Press, 2001.

[4] BiWenCheng. The Particularities of the Translation of Film Language [J] Journal of Ningbo institute of education, 2003 (4). 50-53.

[5] zhao mei, Huang Jinlian. Language characteristics for foreign motion picture translation And translation approaches [J] Jourual of Hefei university of technology 2005, 6 (3) : 133-137. 